\title{
The Influence of Leadership Styles on Employees’ Job Satisfaction in Ethiopian Public Universities
}

\author{
Alemu Muleta Kebede \\ Bahir Dar University \\ E-Mail: alemu.alex2009@gmail.com \\ Getnet Worku Demeke \\ Bahir Dar University \\ E-Mail: wgetme@yahoo.com
}

\begin{abstract}
This study examines the influence of leadership styles on academic job satisfaction in higher education institutions in Ethiopia. The Multifactor Leadership Questionnaire and Job Satisfaction Survey were used to identify the prevailing leadership styles as perceived by employees and to review their satisfaction with the institutions, respectively. The researchers used a cross-sectional survey of academic staff working in selected public universities. A logistic regression analysis was used to assess the relationship between the independent (leadership styles/behaviors) and the dependent (employees' job satisfaction) variables. The findings suggested that transformational leadership influenced positively faculty job satisfaction. The outcome of the research will generate greater awareness on the importance of having leaders whose behaviors/styles increase faculty job satisfaction and ensure organizational effectiveness.
\end{abstract}

Keywords: Leadership, Transformational Leadership, Transactional Leadership Passive/Avoidant Leadership, Job Satisfaction

\section{INTRODUCTION}

People who are working in public and private organizations are discussing the issue of future leadership, whose focus would not be the merits of public or private sector but the scarcity of moral leadership today. Leaders create a culture where their subordinates strive for goal attainment for the success of their organizations. (Donkin, 
2004). They make the most of their potential, skill set and influence to motivate and inspire followers by asserting their authority, enforcing the rules, participating, manipulating the situation and by organizing team efforts.

An academic institution in the 21st century needs leaders to transform them into autonomous, systems-thinking institutions, professional learning communities that can create a high-performing learning environment (Moore, 2009). Sustainable leadership is needed for the long-term success of the organization (Hargreaves and Fink, 2005).

As stated in Kennerly (1989), leadership and employee job satisfaction are the cornerstones of organizational effectiveness. Leadership determines job satisfaction. It affects employees' motivation and commitment both of which affect the performance of an organization, both in the immediate and longer terms. Therefore, improving leadership and management capability is an issue that no organization wishing to achieve long-term success can ignore.

The public sector has been the subject of numerous attempts to define the competence of leaders (Malby, 2006). It provides programs that give these leaders the desired competencies. The need to improve leadership and management skills in public organizations is acute in today's rapidly changing climate. This applies to all types of organizations, from large multi-national companies to the smaller and medium-sized businesses upon which Ethiopia's economy relies or its growth. The transformational leadership style enhances the employees to perform other activities not just the planned (Krishnan, 2005). According to Northouse (2009), transformational leaders transform their followers' emotions, values, and goals for the specific performance based on their talent.

The correlation between leadership style and job satisfaction has been studied in many settings. However, few of these studies emphasized this relationship in higher education institutions. Those studies that do concentrate on this issue were done outside of Ethiopia. Thus, this study examined the relationship between leadership styles and job satisfaction of full-time employees and instructors in some of Ethiopia's public universities.

Furthermore, the study looks at instructors’ perceptions of their leaders' behavior. Thus, the discussions ignore the observed behavior of the leaders or their perceptions. The outcome of the study may contribute to social change by making academic administrators aware of effective leadership models that promote job satisfaction among faculty in higher education institutions. 


\section{STATEMENT OF THE PROBLEM}

Managing in the 21st century is becoming more difficult. The challenges of leadership and management include working in an environment of constant change and the increasing complexity of organizational structures coupled with a tough economic environment and growing competition. Evidence has suggested that new technologies, the knowledge economy, the rise of social media, greater transparency, rising consumer/employee demands and environmental resource concerns present a complex mix of challenges. With the right leadership, an organization can meet these challenges. Leaders can influence employee job satisfaction, commitment and efficiency (Voon, M.L., Lo, M.C., Ngui1, K.S. \& Ayob, N.B., 2011). A capable leader leads followers towards desired organizational goals. Likewise, satisfied employees are likely to invest more effort in their tasks and advance organizational interests. An organization that promotes high employee job satisfaction is also more capable of attracting and retaining skilled employees.

Cognizant of the urgent need to address capacity constraints that hindered the performance of public institutions in Ethiopia, in 1996 the government embarked on a comprehensive Civil Service Reform Program (CSRP) (Government of Ethiopia, 2001). Among the five sub-programs of the reform were top management system and human resource management. The government of Ethiopia sees the development of humanistic values among employees in public institutions as one of its major tasks, one that should be reflected in the leadership styles of the country's public institutions. The challenges for Ethiopia's public institutions of higher education are thus to ensure that leadership practices are in line with this goal and to ensure employees' job satisfaction. This lays the groundwork for the question of which leadership style/behavior is best suited for these purposes. To this end, a critical analysis was based on the theoretical literature and empirical studies on the effect of leadership styles on employee job satisfaction.

The premise of this study is that sustainable and transformational efforts are needed to move academic institutions toward equity, justice and success for Governmental and nongovernmental institutions who have an interest with academic institutions (Saxe, 2011).

There is limited empirical evidence on the subject from Ethiopia itself. We see that new ways are emerging everywhere around the world. At the same time, the world is crying out for leadership. The outcome of the research will be evidence for the value of investing in leadership development in public higher education institutions in Ethiopia. 


\section{Research Question}

The central question of this study was as follows:

Do leadership styles significantly affect employees' job satisfaction?

Which leadership style is adopted by public universities in Ethiopia?

\section{Research Hypotheses}

Researchers have confirmed that the correlation between transactional leadership and transformational leadership was positive and that the correlation between avoidant leadership and job satisfaction was negative (Rizi et al., 2013). Hence, the study proposes three hypotheses.

H1: Employee job satisfaction is positively influenced by a transformational leadership style.

H2: Employee job satisfaction is significantly influenced by a transactional leadership style.

H3: Employee job satisfaction is negatively influenced by a passive/avoidant leadership style.

\section{RESEARCH OBJECTIVES}

\section{General Objective}

This study explores the influence of leadership styles on employees' job satisfaction in public universities in Ethiopia.

\section{Specific Objectives}

The specific objectives of this research are as follows:

1. To examine the effect of a transformational leadership style on job satisfaction

2. To examine the effect of a transactional leadership style on job satisfaction

3. To examine the effect of a passive/avoidant leadership style on job satisfaction

\section{CONCEPTUAL FRAMEWORK}

The objective of this study was twofold. The first objective is to identify the dominant leadership style or styles in Ethiopia's public universities. The second objective is to examine the effect of leadership styles on employees' job satisfaction in selected public universities. The conceptual framework of the study is depicted as follows: 


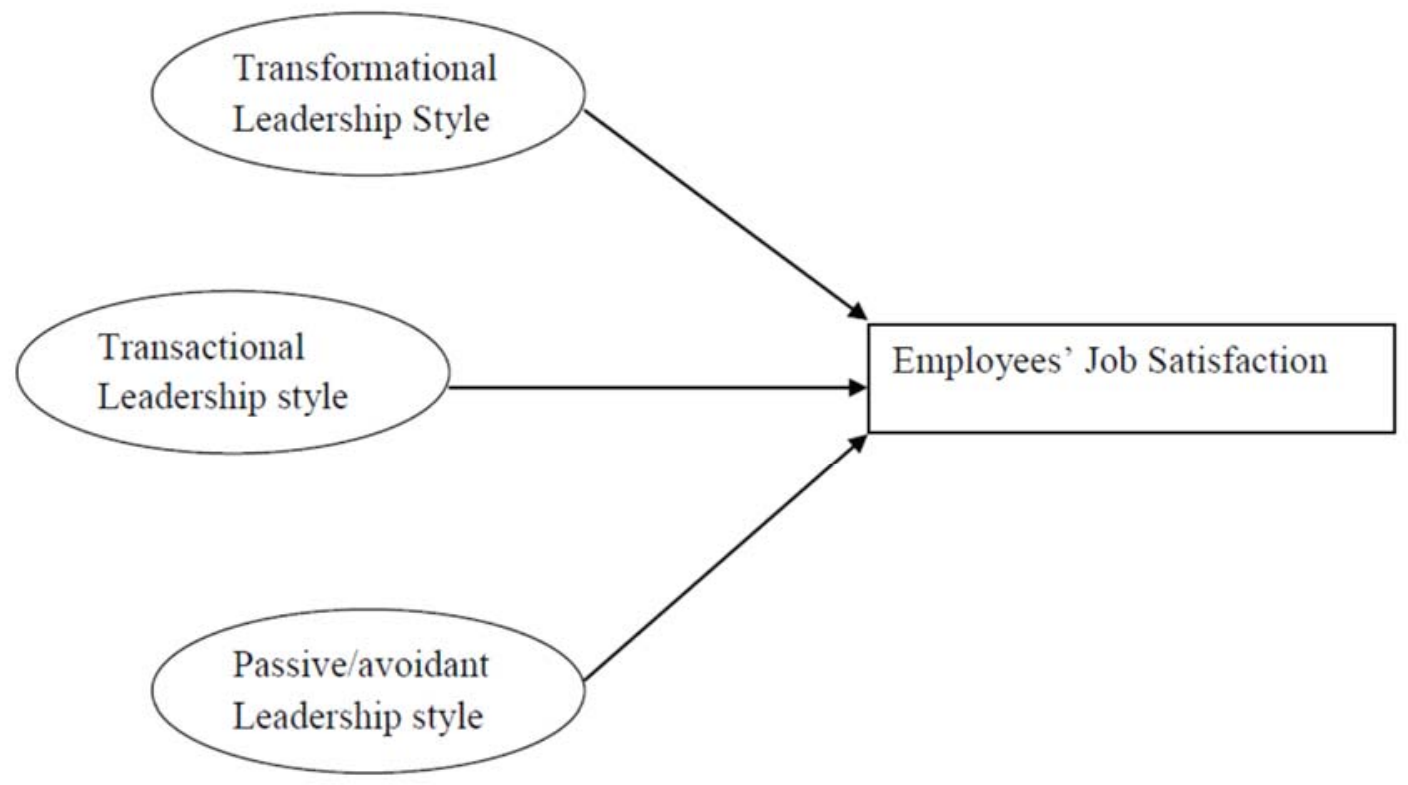

Figure1. Conceptual framework of the research

\section{METHODOLOGY OF THE STUDY}

\section{Research Design}

This study was a cross-sectional survey of employees working in public universities in Ethiopia. A co-relational design was used to elicit information from the quantitative data. A survey is a means of gathering data, as it allows the identification and investigation of relationship patterns among variables (Bryman, 2008 \& Cohen et al., 2007).

\section{Data Type and Source}

Since the objective of this study was to examine the influence of leadership styles on the job satisfaction of academics at a public university, the analysis was based on primary data collected from a sample survey of university faculty. The study also used secondary sources to complement the primary ones and to achieve the research objectives.

\section{Population and Sampling Techniques}

This study explored the perceptions of the employees in public universities in Ethiopia about their leaders' leadership styles and their own job satisfaction. Academic and teaching staff employed by Ethiopia's public universities were the 
target population. However, it was taken into consideration that only those public universities were part of sample where at least 10 years of operation in the industry as a university was applicable. Hence, newer public universities were not included. Four public universities (Addis Ababa University, Bahir Dar University, Mekelle University and Jimma University) were taken out of the target nine oldest public universities in the country. To do so, simple random sampling was used.

There were 8603 full-time employees and faculty in those four universities. Out of those, 382 were taken as the sample. This size was calculated using the sample size determination formula.

Besides the purpose of the study and population size, the three criteria need to be specified to determine sample size: the level of precision (sampling error), the level of confidence or risk and the degree of variability (the nature of the population: homogenous or heterogonous) in the attributes being measured (Israel, 2009). In this study, the population is homogeneous: academic staff working in nearly similar working environments (government-operated universities) all under the regulation of the Ministry of Education. Hence, the sample of 382 respondents reasonably represented the target population of the study.

The formula used to calculate the sample size was;

$$
\mathrm{n}=\mathrm{N} / \mathrm{l}+\mathrm{N}(\mathrm{e})^{2}
$$

Where $\mathrm{n}$ is the sample size, $\mathrm{N}$ is the total population size, and e is the desired level of precision. And the researcher desired a 95\% confidence level and $\pm 5 \%$ precision.

Therefore, the calculation of sample size is as follows:

Therefore, the calculation of sample size is as follows:

$$
\mathrm{n}=\frac{\mathrm{N}}{1+\mathrm{N}(\mathrm{e})^{2}}=\frac{8603}{1+8603(.05)^{2}}=382
$$

Proportional stratified sampling was used to derive the sampling unit from each of the four public universities. This helped to ensure a representative sample in the study even though all the respondents were academic staff in public universities in Ethiopia. The respondents included employees from levels and academic units in the institutions.

Therefore, the number of employees/academic staff taken from each university and their academic units was assigned proportionately. 
From a sample of 382 instructors, 364 responded for a return rate of $95 \%$. Out of the 364 questionnaires, 353 were usable which is enough to represent the target population of the study. Thus, the main analysis in this study was based on sample respondents from four public universities in Ethiopia: Addis Ababa University, Bahir Dar University, Jimma University and Mekelle University.

\section{Data Collection and Instruments}

The study identified the relationship between leadership styles and employees' job satisfaction. Three survey instruments were used: the Multifactor Leadership Questionnaire (MLQ) which measures leadership style (Bass \& Avolio, 1997), Job Satisfaction Survey (JSS) which measures employees' job satisfaction and a brief demographic survey (Spector, 1985; 1997; 2011; Watson, Thompson \& Meade, 2007). All questions were scored along a 5 -point Likert scale $(0=$ not at all, $1=$ once in a while, $2=$ sometimes, $3=$ fairly often and $4=$ frequently, if not always). To be as comprehensive as possible, this study used the full range of leadership styles: transactional, transformational and passive/avoidant.

For the sake of efficiency and timeliness, administration of the questionnaires was achieved through personal contacting, assistants/enumerators and networking. An open-ended question was added to solicit views from respondents without restrictions. Other data were gathered from records at the Ministry of Education, university files, operating manuals and research, seminar papers, annual reports, statistical abstracts, magazines, newspapers and journals.

\section{Method of Data Analysis}

Since variables were measured with numeric indicators, quantitative analysis methods were employed. After careful collection and coding of data, and the entry of those data into SPSS, both descriptive and inferential statistics were calculated for each variable of interest. Accordingly, binary logistic regression analysis to see if there is a significant relationship between the leadership styles and employees' job satisfaction. Logistic regression is appropriate to test the primary hypotheses for dependent variables measured on a binary scale (Siemsen, Roth, \& Oliveira, 2010). Logistic regression analysis explains likelihood variations in the dependent variable job satisfaction because of the change in the independent variables/leadership styles. Statistical analysis was done using the Statistical Package for Social Sciences (SPSS) version 20. 


\section{FINDINGS, DISCUSSIONS AND IMPLICATIONS}

The purpose of this study was to examine the effects on job satisfaction of instructors' perceptions of transformational, transactional, and passive/avoidant leadership styles at Ethiopia's public universities. The study considered the perspectives or opinions of academic staff or teaching personnel regarding the behaviors and /social competencies of their leaders. The study attempted to link the attributes and behaviors of the leader (leadership styles) to the job satisfaction of employees/academic staff. The results of descriptive statistics, cross-tabulation and binary logistic regression from 353 samples are given here. Statistical analysis was used to conceptualize the effect of leadership behavior of leaders on the job satisfaction of university teaching staff.

\section{The Dominant Leadership Style}

Table 1 contains the summary statistics for the scales of leadership styles and job satisfaction. It results from taking means across the constituent scale items.

By identifying the leadership scale with the highest score we can learn which leadership style is the dominant one in the universities.

Table 1 Descriptive Statistics of the three Main Leadership Styles

\begin{tabular}{lcccc}
\hline \multicolumn{1}{c}{ Variables } & Minimum & Maximum & Mean & SD \\
\hline Transformational leadership & .00 & 3.40 & 1.87 & .77 \\
\hline Transactional leadership & .50 & 3.50 & 1.76 & .72 \\
\hline Passive/Avoidant leadership & .25 & 3.63 & 1.93 & .79 \\
\hline Job satisfaction & 1.86 & 4.53 & 3.30 & .46 \\
\hline
\end{tabular}

The transformational leadership scale ranges from 0.00 to 3.40 with a mean of 1.87 (SD $=0.77)$. The transactional leadership scale ranged from 0.50 to 3.50 with a mean of 1.76 ( $\mathrm{SD}=0.72$ ). In addition, the result on the passive/avoidant scale ranged from 0.25 to 3.63 and an average of 1.93 (SD =0.79). The result of the dependent variable, job satisfaction, ranged from 1.86 to 4.53 with an average of 3.30 (SD = 0.46).

The most dominant style was passive/avoidant leadership style with the highest mean of 1.93 (SD=0.79). 
The transformational leadership style was the second most common/dominant type with an average of 1.87 (0.77). Transactional leadership was found to be the least common style with an average of $1.76(0.72)$.

\section{Data Analysis Using Binary Logistic Regression Model}

A binary logistic regression model is useful when researchers want to predict the presence or absence of a characteristic of an outcome variable. Unlike a linear regression model, it is suited to situations in which the dependent variable is dichotomous. Therefore, in the current study, logistic regression coefficients can be used to estimate likelihood of outcome variables for each of the independent variables in the model. Table 2 presents the influence of the three leadership styles on university employees' job satisfaction.

\section{Relationship between Leader Behaviors and Employees’ Job Satisfaction}

The hypotheses (H1, H2, and H3) were that "Employee job satisfaction is significantly influenced by transformational leadership, transactional, passive/avoidant leadership styles”

To test the effect of transformational leadership style on faculty job satisfaction, a logistic regression model was employed. According to the results in Table 2, for each one-unit increase on the transformational leadership scale, the odds of being satisfied increased by 2.097. This implies that transformational leadership style has a great impact on employees' job satisfaction. When we look at transactional leadership style, a one-unit increase or improvement in transactional leadership style increases employees' job satisfaction by 1.25 but the model (adjusted odds ratio) reflects it is statistically insignificant at 0.05 .Like transactional leadership style, passive/avoidant leadership style is still insignificant at 0.05. Thus, among the three leadership styles only transformational leadership style has a clearly positive significant effect on faculty job satisfaction. The transactional and passive leadership styles are statistically insignificant.

Table 2 Logistic Regression Model

\begin{tabular}{llllll}
\hline VARIABLES IN EQUATION & COR $^{\mathbf{1}}$ & P. value & $\mathbf{B}$ & AOR $^{\mathbf{2}}$ & P. Value \\
\hline Transformational leadership & 2.57 & .000 & .741 & 2.097 & .001 \\
\hline Transactional leadership & 1.966 & .000 & .223 & 1.250 & .271 \\
\hline Passive/Avoidant leadership & 1.422 & .017 & .203 & 1.225 & .217 \\
${ }^{1}$ Crude odds ratio & & & & & \\
${ }^{2}$ Adjusted odds ratio & & & & &
\end{tabular}




\section{CONCLUSIONS}

The objective of this study was to examine the influence of leadership styles on employees' job satisfaction in public universities in Ethiopia. The analysis was based on primary data collected from a sample survey of employees in four public universities. The study identified that leadership behaviors of leaders in the sample universities influenced the satisfaction of academic staff. The results revealed that instructors prefer a leader who exhibits a transformational style/behavior. It stands to reason that transformational leaders maximize the autonomy of academic staff. Consequently, the instructors' preference for transformational leaders will reinforce the basics for the functioning of the universities (i.e. organizational structures) as they are in increasingly changing environment. This indicates that the challenge for education is in enabling academic staff to coordinate their work, not in maximizing their autonomy.

Several recommendations are proposed based on these findings. Academic leaders can propagate the prevailing reality in their respective organization and refine their leadership styles to suit the preferences of their faculty members. Weaknesses in educational institutions leadership and management skills are holding back Ethiopia's competitiveness in higher education. Therefore, the need for improved management skills across universities should be a top priority.

Senior academic administrators should clearly identify transformational leaders in their organizations so that these leaders will help them to train and mentor future leaders. Furthermore, academic administrators should recognize and learn the behavioral theory of leadership. They will then be in a position to offer professional development and training opportunities for transformational leadership for present and future academic leaders. The training and professional development programs for university leaders should teach them to recognize the organizational climate and to influence, inspire and guide the work of teaching staff and teams their by ensuring their job satisfaction.

Those who seek leadership positions in higher education institutions should understand and acquire the skills of transformational leaders. This study calls for attention to the inner world of instructors. Improving leadership and management skills that will unlock the potential of Ethiopian public universities, allowing them to keep their faculty satisfied, take advantage of resources and opportunities available to them and achieve sustainable prosperity.

Since the evidence for this study is only from four selected public universities in Ethiopia, the results may not apply to for-profit, private academic institutions and/or private sector corporations. Future research should explore the profit and nonprofit 
making sector, government departments and other organizations in order to analyze the relationship between leadership styles and job satisfaction in addition other outcomes such as organizational performance. The study can be enhanced by including or considering other factors that might contribute to the job satisfaction of academic staff.

\section{REFERENCES}

Bass, B. M. \& Avolio, B. J. (1997) Full range leadership development: Manual for the multifactor leadership questionnaire, CA, Mind Garden. http://dx.doi.org/10.4135/9781483349107

Bryman, A. (2008). Social Research Methods. (3rd ed.) Oxford: Oxford University Press.

Cohen, L., Manion, L. \& Morrison, K. (2007) Research Methods in Education. 6th edn. London: Routledge. http://dx.doi.org/10.4324/9780203224342

Donkin, R. (2004). Public versus private sector leadership. European Journal of Social

Sciences.

15(3).

http://www.richarddonkin.com/x_leadership_public_vs_private.htm

Government of Ethiopia (2001) 'Ethiopian Civil Service Reform Program: A Report by a Taskforce on the Ethiopian Civil Service Structure and Performance'. Addis ababa:GoE.

Hargreaves, A., \& Fink, D. (2005). Sustainable leadership. San Francisco, CA: Jossey- Bass. http://dx.doi.org/10.4135/9781446288290.n11

Israel, G.D. (2009). Determining sample size. Gainesville, FL: Florida State University, Cooperative Extension Service. Retrieved 29 November, 2015 from https://edis.ifas.ufl.edu/pd005.

Kennerly, S. M. (1989). Leadership behavior and organizational characteristics: Implications for faculty satisfaction. Journal of Nursing Education, 28(5), 198-202.

Krishnan, V. R. (2005). Transformational leadership and outcomes: role of relationship duration. Leadership and Organization Journal, 26(5-6), 442-457. http://dx.doi.org/10.1108/01437730510617654

Malby, B. (2006). How Does Leadership Make Difference to Organizational Culture and Effectiveness? An overview for the public sector, Northern Leadership Academy. Retrieved from http://www.cihm.leeds.ac.uk/wpcontent/uploads/2014/03/new_nla_paper_leadership_and_culture_2_.pdf

Moore, B. (2009). Emotional intelligence for school administrators: A priority for school reform. American Secondary Education 37(3) summer 2009.Retrieved from 
https://pdfs.semanticscholar.org/dc65/d6723dcdb47ef5180e47e5990f909f65ccb2.pdf Northouse, P. G. (2009). Leadership, Theory and Practice (5th ed.). United States of America: Sage.

Rizi, R.M., Azadi, A., Farsani, M.E. \& Aroufzad, S. (2013). Relationship between leadership styles and job satisfaction among physical education organizations employees. European Journal of Sports and Exercise Science, 2013, 2 (1):7-11 http://scholarsresearchlibrary.com/archive.html

Saxe, D. (2011). Relationship between Transformational Leadership and the Emotional and Social Competence of the School Leader. Dissertations.Paper63. Retrieved from http://ecommons.luc.edu/luc_diss/63

Siemsen, E., Roth, A., \& Oliveira, P. (2010). Common method bias in regression models with linear, quadratic, and interaction effects. Organizational Research Methods, 13(3), 456-476. http://dx.doi.org/10.1177/1094428109351241

Spector, P. E. (2011). Job Satisfaction survey. Retrieved form. http://chuma.cas.usf.edu

Spector, P. E. (1997). Job satisfaction: Application, assessment, causes, and consequences. Thousand Oaks, CA: Sage. http://dx.doi.org/10.4135/9781452231549

Spector, P. E. (1985). Measurement of human service staff satisfaction: Development of the job satisfaction survey. American Journal of Community Psychology, 13, 693-713. http://dx.doi.org/10.1007/BF00929796

Voon, M.L., Lo, M.C., Ngui1, K.S. \&Ayob, N.B. (2011). The influence of leadership styles on employees' job satisfaction in public sector organizations in Malaysia. International Journal of Business, Management and Social Sciences, 2( 1), 24-32.

Watson, A. M., Thompson, L. F., \& Meade, A. W. (2007, April). Measurement Invariance of the Job Satisfaction Survey across Work Contexts. Paper presented at the 22nd Annual Meeting of the Society for Industrial and Organizational Psychology, New York. Nom http://www4.ncsu.edu/ awmeade/Links/ConferencePapers.htm 